\title{
Managing the Transition from Concussion to Return to Learn in Postsecondary Education: Strategies Based on Principles of UDL
}

\author{
Gail Frost \& Maureen Connolly \\ Brock University
}

DOI: $10.22329 /$ celt.v11i0.4976

Concussion is a functional brain injury that can produce physical, cognitive, emotional and sleep-related symptoms that impede student learning. The Return-to-Learn protocol is effective for elementary and high school-aged students, but it is difficult to implement in a postsecondary setting as it requires a level of monitoring not generally available through college or university student wellness centres. As a result, course instructors are often given the task of providing accommodations to help students recovering from concussion. This paper discusses the challenges facing the postsecondary student recovering from concussion and provides accommodation ideas and examples that instructors may find helpful.

Les commotions cérébrales sont des lésions fonctionnelles au cerveau qui peuvent provoquer des symptômes physiques, cognitifs et émotionnels ainsi que des troubles du sommeil qui ont des répercussions sur l'apprentissage de l'étudiant. Le protocole de reprise des études est efficace pour les étudiants du primaire et du secondaire, mais, comme il nécessite un certain degré de surveillance qui n'est pas communément offert dans les centres de bien-être étudiants collégiaux ou universitaires, sa mise en ouvre en contexte postsecondaire est ardue. Par conséquent, on demande souvent aux enseignants de mettre en place des mesures d'adaptation pour aider les étudiants qui se remettent d'une commotion cérébrale. Cet article traite des difficultés auxquelles sont confrontés les étudiants qui se remettent d'une commotion. II comprend des idées de mesures d'adaptation et des exemples que les enseignants pourraient trouver utiles.

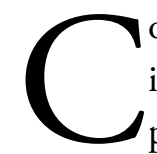

oncussion is a traumatic brain injury induced by biomechanical forces that can produce physical, cognitive, emotional and sleep-related symptoms. These symptoms may appear immediately or several hours, or days, after the injurycausing incident. Because concussion is a disturbance in brain function, rather than damage to brain structure, it is not identifiable using standard imaging techniques such as X-ray, MRI or CT scan. Diagnosis and management rely heavily on monitoring injury symptoms and how they change. In many cases, these symptoms may resolve within two weeks for adults, but recovery has been shown to take longer in children and adolescents (Crowe et al., 2016; Purcell 
et al., 2016). Research examining concussion recovery in young adults (i.e. 18-22 years) is limited (Zuckerman et al., 2012). Current best practices for identifying and managing concussion are reported after each meeting of the International Conference on Concussion in Sport (McCrory et al., 2017) and suggest that a large majority of athletes recover clinically within one month of injury. The reported incidence of concussion is rising and we are seeing more students in our post-secondary classes who have sustained this injury, some of whom are still dealing with symptoms. The 6-step Return-to-Learn protocol (Parachute, 2016) works well to manage the return to the classroom for elementary and high school-aged students; however, it is difficult to implement in a postsecondary setting, as it requires individual management, gradual resumption of schoolwork and reintegration into classes, and potentially extensive modifications in workload and assessment (McGrath, 2010). While some of these services may be available to college or university students through campus wellness centres, often these centres are limited to assisting cases of documented chronic or permanent disability, leaving individual course instructors with the responsibility for helping students with acute concussion symptoms that will resolve in a relatively short period. At our institution, Student Health Services (SHS), the Athletic Therapy Clinic and interested faculty created a Concussion Medical Certificate to formalize the health care protocol and keep instructors apprised of the student's situation, with the help of the Registrar's Office. With the student's consent, this document is sent to their course instructors and provides information on date of diagnosis of concussion, anticipated date of return to class, the SHS monitoring plan and some general suggestions for accommodations to enable the student to complete required course work. Removing the responsibility of reporting their situation to their instructors eliminates one taxing cognitive task for the student from the early stage of their recovery. The Concussion Medical Certificate protocol also includes options for an 'Incomplete' grade, which allows the student eight additional weeks after the end of term to complete course work, or a back-dated (to avoid a financial penalty) withdrawal from courses that cannot be completed, even with assistance. Our institution does not currently have a specific Leave of Absence option for undergraduate students.

An extended period of complete rest does not appear to be helpful in concussion recovery and a gradual, progressive return to activity (cognitive and physical), that allows the student to stay below the thresholds that make symptoms worse, can be initiated after the immediate post-impact rest period of 24-48 hours (Grool et al., 2016; McCrory et al., 2017). Activities with a heavy reliance on executive processing functions will likely be more stressful for students managing concussion symptoms and a return to learning following clearance. Subject matter that expects problem solving or attention in a progressive, interdependent and mostly linear fashion will be challenging (e.g., math, logical reasoning, expository writing) (Ransom et al., 2015). Anxiety is a common finding after concussion and in students it can be exacerbated by concerns about falling behind in school and their ability to complete courses (Sady et al., 2011). It should be noted that encouraging students to 'try harder' when they are displaying postconcussion symptoms is not only unhelpful, but it can make the situation worse, as an 'energy crisis' within brain cells caused by metabolic dysfunction and a disruption of cell communication is already occurring in the immediate post-impact period (Giza \& Hovda, 2014; Sady et al., 2011). Determining how much is too much for the student returning to class may be a trial and error process at first. The instructor can focus efforts to make helpful accommodations by initiating a discussion with the student about the parts of the course that seem more difficult compared to before the concussion, the length of time after which it becomes hard to focus or fatigue sets in, whether the student's ability to concentrate, read or work at normal speed is related to the time of day, 
and whether there are specific things in the classroom environment that seem to distract the student ("Returning to School After a Concussion," 2017).

Before considering the specific challenges of physical classroom spaces, online learning environments and course design with respect to postconcussion symptoms, the authors will describe a conceptual framework from which to reimagine content, assessment and course organization in ways that will support both the teaching and learning challenges associated with returning to learn following concussion. This framework uses the principles of Universal Instructional Design, also referred to as Universal Design for Learning (UDL). UDL can be helpful in meeting the student's concussion-related needs, especially in the physical and cognitive domains. The tenets of UDL are that it is flexible, functional, consultative, individualized or customized, and uses multiple means of engaging with and being assessed on course content and process ("About Universal Design for Learning," n.d.; CAST, 2011). Instructors committed to UDL understand and accept that accommodations must be planned and designed ahead of time; that is, the instructor anticipates the likelihood that students in the class will need accommodations in some aspect of the course design and delivery, and prepares for this eventuality in terms of content, pedagogy, assessment, timing, options and alternatives, and selfdirectedness (Tobin, 2014). However, it is also the case that the flexibility of UDL makes it an ideal framework to support individualized accommodations for students recovering from concussion once the course is already under way. UDL can be applied to both face to face and online environments ("Universal Design for Learning," n.d.). An example of a UDL option that is useful for students returning to the classroom after concussion is the circle of friends (COF) (James \& Leyden, 2010). When an instructor implements the COF as an accommodation, he or she consults with the person requiring or requesting the accommodation prior to setting up the circle. Then the instructor invites students in the class who are interested in supporting a classmate in an accommodation for learning to contact the instructor. Once three to five students have indicated interest, the instructor can facilitate the COF. COF meets with the instructor and the student requiring/requesting the accommodation and plans a weekly map of the course as well as designing alternatives to the course processes that need adapting. Weekly meetings gradually may loosen to bi-weekly meetings and often transition to less and less involvement by the instructor and more active innovation and generation of alternatives by the students. Indeed, as the student's symptoms disappear, it is likely that there will be less and less involvement overall. Students in the COF also may disperse the forms and frequency of supports for accommodation so that turn-taking and strength-based decision-making and engagement can occur. The members of the COF also negotiate with the instructor to adapt their own assessment to account for the time demands and class participation demands of the COF. A COF can be implemented with a student experiencing the symptoms of, and the returning from, concussion in both face to face and online contexts. Indeed, a COF would allow a student needing accommodation to avoid 'screen time' but remain connected to the course in an online scenario and would allow a student in a face to face context the possibility of supported planning for the inevitable executive function demands that missing classes and assessments would entail.

\section{The Physical Teaching Space}

There are many features of a physical teaching space that can be modified or addressed to assist students (An Educator's Guide to Concussions, 2012; "Helping Students Recover," 2017). Two commonly reported symptoms after concussion are dizziness or balance problems and sensitivity to light. 
In a classroom with theatre-style seating, i.e. the floor slopes downward toward the front of the room, providing a seating option at the back of the room will ensure that the student does not have to negotiate the slope to find a seat. If the classroom has windows, seating the student away from the windows and giving them the option of wearing a hat with a brim or sunglasses can be helpful. If dimming the overhead lights is possible, consider doing this to the extent that all students still have the light needed to perform the tasks required for your class. Other symptoms often reported after concussion include fatigue, sensitivity to noise, fuzzy or blurred vision and an inability to concentrate and remember material. Fatigue can be managed by allowing the student to take a break when needed and if they are using the seat near the door they can slip out of class unnoticed. If sensitivity to noise is an issue, consider closing classroom doors, using a microphone to clarify the sound of your voice, if necessary, or being near the student when using spoken communication, and suggesting the student use earplugs or headphones when practical. Allowing the student to leave class five minutes early to avoid typical class change hall crowds and noise may also help. Your teaching style may already address the issue of concentration by breaking up lectures using strategies such as 'Think-Pair-Share' (Cameron, 1999), or separating class time into 'chunks' with breaks or a change of activity. Poor memory can be addressed by allowing students to record your lectures or by connecting the student with a classmate who will share their notes. If using PowerPoint, slide design should incorporate UDL principles for layout and structure, text, graphics and images, tables and charts and audio and video (for specific examples of each, see "Creating Universal PowerPoint Content," n.d.).

\section{The Online Teaching Space}

Both course content and course organization must be considered in relation to the students' symptoms. If the students' symptoms are sensitivity to light, or fuzzy or blurred vision, you will have to consider how much of your course materials can be converted to audio formats, as well as considering the pace and motion of your screen, the font style and size of your texts, the colour contrast and backgrounds of your materials, and the organization of pages in terms of distractions, tabs and clicks. Modifying the brightness of the screen, and having consistent placement of materials and clarity of instructions will also decrease the duration and amount of processing of visual material. For noise sensitivity, an instructor can aim for a consistent volume of audio material, an absence of background noise, and arranging for discussions to be well spaced or in different spaces. While the sensorial challenges of concussion can be challenging in terms of fatigue, frustration, and physical discomfort and distress, the processing, memory and concentration challenges are also noteworthy and need careful attention and consideration as well. Consider re-organizing your presentation of materials and your assessments into smaller, more manageable 'chunks' or blocks of material and time. $\mathrm{Be}$ as consistent as possible in terms of format and order of presentation across pages in the learning management system you use, so that the learner can rely on predictable structures and hence can reduce anxiety associated with being on the alert for ongoing changes and their concomitant decision making and planning. Having an audio version of course material available reduces the cognitive load compared to multimedia or visual formats. Mayer and Moreno (2003) provide a more detailed analysis of cognitive overload and ways to alleviate it.

\section{Course Organization}

Consider your deadlines and forms of submission in more flexible ways and re-imagine your volume of work, choosing threshold concepts to 
guide the learning, and readings and processes that have clear focus on and relevance for the learning of these concepts. Provide logical and succinct summaries and you will encourage your students to develop these skills as well. For the ongoing support that students experiencing concussion will need, develop prompts and reminders, read material about course design and be more attuned to relevant materials on adapting and accommodating for learning. You may also implement a COF option when the opportunities to do so are appropriate and congruent with the students requiring accommodation, and the demands of the course.

The following table lists common postconcussion symptoms and presents ideas to consider implementing in your course if you have students who require some accommodation during recovery.

\section{Table 1}

\begin{tabular}{ll}
\hline Sensitivity to light & What's the pace and motion of your screen material? \\
Sensitivity to noise & What font weight and style are you using? e.g. sans serif fonts are \\
Fuzzy or blurred vision & easier to read. \\
& Colour choices of text and backgrounds? e.g. use highly contrasting \\
text and background colours. Avoid red and green. & Are volume levels of recorded materials consistent? \\
& Are there audio versions of any of your course materials? Listening \\
creates less cognitive load than watching or a combination of listening & and watching. \\
& Resources: \\
"Creating Universal PowerPoint Content": \\
https://www.uky.edu/udl/powerpoint \\
"Fonts": \\
https://webaim.org/techniques/fonts/\#font size \\
"UDL \& Accessibility Checklist": \\
$\underline{\text { https://www.uky.edu/udl/udl-accessibility-checklist }}$
\end{tabular}

\begin{tabular}{ll}
\hline Fatigue & Have asynchronous options for participation, office hours, group \\
Poor concentration & work. e.g. use Word Online or Google Docs for collaborative tasks \\
Poor memory & within groups. \\
& Use 'due by' deadlines rather than 'due on' - 1 week rather than 12 \\
& hours to do tests or assignments. \\
& Don't require students to 'multitask'. \\
& Break tasks into smaller sections. \\
& Split tests and exams into smaller sections done on different days. \\
& Use alternative testing formats - e.g. oral exams, one-on-one testing, \\
& quiet testing. \\
\hline
\end{tabular}


Reduce repetition of work - e.g. assign only even-numbered problems for homework.

Resources:

"Helping Students Recover from a Concussion":

https://www.cdc.gov/headsup/pdfs/schools/tbi classroom tips for tea

chers-a.pdf

\begin{tabular}{|c|c|}
\hline Slowed information processing & Reduce the number and size of assignments. \\
\hline Slow to answer questions & Adjust "due" dates; allow for extra time. \\
\hline \multirow[t]{11}{*}{ Takes longer to get work done } & Exempt/postpone large test/projects. \\
\hline & $\begin{array}{l}\text { Use alternative testing formats - quiet testing, one-on-one testing, oral } \\
\text { testing. }\end{array}$ \\
\hline & $\begin{array}{l}\text { Provide class notes, written instructions, written outlines for larger } \\
\text { tasks. }\end{array}$ \\
\hline & Allow recording of lectures. \\
\hline & Provide explicit feedback orally and in writing. \\
\hline & Resources: \\
\hline & McGrath, 2010 \\
\hline & An Educator's Guide to Concussions in the Classroom: \\
\hline & http://www.nationwidechildrens.org/concussions-in-the-classroom \\
\hline & "Helping Students Recover from a Concussion": \\
\hline & https://www.cdc.gov/headsup/pdfs/schools/tbi_classroom tips for tea \\
\hline
\end{tabular}

\begin{tabular}{|c|c|}
\hline $\begin{array}{l}\text { Difficulty organizing or expressing } \\
\text { ideas }\end{array}$ & $\begin{array}{l}\text { Avoid multitasking. } \\
\text { Break tasks into smaller sections. } \\
\text { Use organizational charts, concept maps or mind maps. } \\
\text { Encourage use of a planner. } \\
\text { Allow demonstration of learning in alternative fashion - a video or } \\
\text { audio piece instead of a written document. } \\
\text { Resources: } \\
\text { Audacity - for recording/creating audio files } \\
\underline{\text { http://www.audacityteam.org/home/ }} \\
\text { Camtasia or Snagit - for creating videos (free trials are available) } \\
\underline{\text { https://www.techsmith.com/ }}\end{array}$ \\
\hline $\begin{array}{l}\text { Short term memory issues } \\
\text { Difficulty learning new } \\
\text { Information }\end{array}$ & $\begin{array}{l}\text { Link new information to already known information. } \\
\text { Break tasks into smaller sections. } \\
\text { Use organizational charts. }\end{array}$ \\
\hline
\end{tabular}


Forgetting instructions

Appearing disorganized
Provide class notes, written instructions, written outlines for larger tasks.

Repeat the instructions out loud.

Encourage use of a planner.
Impaired executive processing

Negotiating learning management

systems or course syllabus

documents
Learning management system:

How is your material organized?

Sequencing to get started - how many clicks does it take to get to a document?

Maintain logical., consistent placement of online materials, e.g. major units or modules always listed on the left margin of the screen.

Are hard copies of your documents available? Are audio versions of any of your materials available?

Do your videos have captions?

Submitting assignments - could you make oral or video submission possible, rather than a 'paper'?

If students are required to post comments, is an oral report possible instead?

Is Skype required for distance contact, or could phone be an option?

Course syllabus:

Put 'need to know' information on page 1 in a logical sequence.

Provide details on the following pages.

Resources:

Mayer \& Moreno, 2003

"UDL Accessibility Checklist":

https://www.uky.edu/udl/udl-accessibility-checklist

"Universal Design for Learning in Higher Education":

http://udloncampus.cast.org/page/planning syllabus\#.WchD9YprzVp
Because the presentation of symptoms and progression of recovery after concussion is unique to each individual., the accommodation plan any instructor devises will also need to be unique and tailored to address the student's specific concerns and deficits. Combining concussion-related resources with ideas from other sources like UDL is an effective way of creating a workable plan. By making your way through this process, there is every chance that you will become a more thoughtful and effective teacher not only for the student requiring or requesting accommodations, but also for all students who will benefit from a more carefully considered alignment of content, pedagogy, organization and assessment. 


\section{References}

About Universal Design for Learning. (n.d.). Retrieved September 30, 2017, from CAST website: http://www.cast.org/ourwork/about-udl.html\#.Wc6TYdFrzcs

An educator's guide to concussions in the classroom (2nd ed). (2012). Retrieved September 30, 2017, from Nationwide Children's website: http://www.nationwidechildrens.org/concus sions-in-the-classroom

Cameron, B. (1999). Green guide \#2: Active learning. Halifax, NS: Society for Teaching and Learning in Higher Education.

CAST (2011). Universal design for learning guidelines version 2.0. Wakefield, MA: Author.

Creating universal PowerPoint content. (n.d.). Retrieved September 30, 2017, from University of Kentucky website: https://www.uky.edu/udl/powerpoint

Crowe, L., Collie, A., Hearps, S., Dooley, J., Clausen, H., Maddocks, D.,...Anderson, V. (2016). Cognitive and physical symptoms of concussive injury in children: A detailed longitudinal recovery study. British Journal of Sports Medicine, 50(5), 311-316.

Fonts. (2017). Retrieved September 30, 2017, from WebAIM website: https://webaim.org/techniques/fonts/\#font_ size

Giza, C., \& Hovda, D. (2014). The new neurometabolic cascade of concussion. Neurosurgery, 75(4), S24-S33. doi:10.1227/NEU.0000000000000505

Grool, A., Aglipay, M., Momoli, F., Meehan III, W., Freedman, S., Yeates, K.,...Zemek, R. (2016). Association between early participation in physical activity following acute concussion and persistent postconcussive symptoms in children and adolescents JAMA, 316(23), 2504-2514. doi:10.1001/jama.2016.17396

Helping students recover from a concussion: Classroom tips for teachers. (2017). Retrieved September 30, 2017, from Centers for Disease Control and Prevention website: https://www.cdc.gov/headsup/pdfs/schools/ tbi_classroom_tips_for_teachers-a.pdf

James, A., \& Leyden, G. (2010). Putting the circle back into Circle of Friends: A grounded theory study. Educational \& Child Psychology, 27(1), 52-63.

Mayer, R. E. \& Moreno, R. (2003). Nine ways to reduce cognitive load in multimedia learning. Educational Psychologist, 38(1), 43-52. doi:10.1207/S15326985EP3801_6

McCrory, P., Meeuwisse, W., Dvořák, J., Aubry, M., Bailes, J., Broglio, S.,...Vos, P. (2017.) Consensus statement on concussion in sport - The 5th international conference on concussion in sport held in Berlin, October 2016. British Journal of Sports Medicine, 51, 838-847. doi: 10.1136

McGrath, N. (2010). Supporting the studentathlete's return to the classroom after a sportrelated concussion. Journal of Athletic Training, 45(5), 492-498.

Parachute's protocol for Return to Learn after a concussion. (2016). Retrieved September 30, 2017, from Parachute website: http://horizon.parachutecanada.org/en/artic le/parachutes-return-to-learn-protocol/

Returning to school after a concussion: A fact sheet for school professionals. (2017). Retrieved September 30, 2017, from Centers for Disease Control and Prevention website: https://www.cdc.gov/headsup/pdfs/schools/ tbi_returning_to_school-a.pdf

Sady, M., Vaughan, C., \& Gioia, G. (2011). School and the concussed youth - 
Recommendations for concussion education and management. Physical Medicine and Rehabilitation Clinics of North America, 22(4), 701-719. doi:10.1016/j.pmr.2011.08.008

Tobin, T.J. (2014). Increase online student retention with universal design for learning. The Quarterly Review of Distance Education, 15(3), 2014, pp. 13-24

UDL \& accessibility checklist. (n.d.) Retrieved September 30, 2017, from University of Kentucky website: https://www.uky.edu/udl/udl-accessibilitychecklist

Universal Design - Best practices for online learning. (2016). Retrieved September 30, 2017, from OpenEd Open Learning and Educational Support website: http://ud.opened.uoguelph.ca/?_mid_=161 6

Universal design for learning in higher education. (n.d.). Retrieved September 30, 2017, from UDL on Campus website: http://udloncampus.cast.org/home\#.Wc7B HIprzVo

What is a circle of friends? (2015). Retrieved September 30, 2017, from Inclusive Solutions website: https://inclusivesolutions.com/circles/circle-of-friends/whatis-a-circle-of-friends/

Zuckerman, S. L., Lee, Y. M., Odom, M. J., Solomon, G. S., Forbes, J. A., \& Sills, A. K. (2012). Recovery from sports-related concussion: Days to return to neurocognitive baseline in adolescents versus young adults. Surgical Neurology International, 3, 130. http://doi.org/10.4103/2152-7806.102945

\section{Biographies}

Dr. Gail Frost is an associate professor in the Department of Kinesiology at Brock University. She teaches courses in functional anatomy, sports injury prevention and care, and therapeutic exercise and is committed to finding effective ways to help students learn.

Dr. Maureen Connolly is a Professor of Physical Education and Kinesiology in the Faculty of Applied Health Sciences, Brock University. Maureen's teaching and research interests include curriculum, stressed embodiment, dance $\&$ movement education, and Freirian approaches to teaching and learning. Her theoretical dispositions are semiotic, phenomenological, post-colonial, irreverent and quixotic. 